\title{
On the Rationality of Bundled Rebate Program in Modem Chip Industry: an Analysis on Qualcomm's Case
}

\author{
Youqiong $\mathrm{Ai}^{1} \cdot$ Thomas $\mathrm{Y} . \mathrm{Lu}^{2}$ (D)
}

Received: 15 February 2019 / Revised: 10 June 2019

Accepted: 18 June 2019/Published online: 29 June 2019

(C) The Author(s) 2019

\begin{abstract}
This paper examines the motivations of a patent holder, for example, Qualcomm holding many standard essential patents (SEPs) on modem chips, to implement a bundled rebate program for its customers, Apple for instance, under the risk of violating antitrust law. This study originates from the lawsuit between Qualcomm, Federal Trade Commission (FTC), and Apple. In early 2017, both FTC and Qualcomm's customer, Apple, sued Qualcomm for violating antitrust law. Qualcomm was alleged to have manipulated "web of contracts" by implementing so-called no license, no chips policy to achieve its anticompetitive purpose. By addressing the case law of antitrust regime related to bundled rebate and loyalty discount, we understand legal risks that Qualcomm might face. Moreover, in this paper, we build a gametheoretical model to explore business reasons why Qualcomm insists on implementing the bundled rebate and loyalty discount program, regardless of latent legal risks. It is shown that Qualcomm might desire to mitigate future loss from price war with potential competitors. Finally, this article concludes with expectations for future studies on the impact of the Federal Court if SEPs and modem chips cannot be bundled together.
\end{abstract}

Keywords Bundled rebate program · Patent licensing · Modem chip industry · Law and business

Youqiong Ai and Thomas Y. Lu contribute to this paper equally.

Youqiong Ai

yqai16@fudan.edu.cn

Thomas Y. Lu

y.lu@wustl.edu

1 School of Management, Fudan University, Shanghai 200433, China

2 Law School, Washington University in St. Louis, St. Louis, MO 63130, USA 


\section{Introduction}

Bundled rebate and loyalty discount are two traditional incentives to sustain the customer relationship between a supplier and a manufacturer. In the presence of bundled rebate, the manufacturer buying products and/or other services altogether can receive a fixed amount of rebate from the supplier in return. As a result, this rebate can constantly and exclusively tempt the manufacturer into buying products or other services together from that specific supplier. Loyalty discount, similar to bundled rebate, is another incentive for exclusive procurement. In practice, bundled rebate and loyalty discount sometimes are combined into a total fixed number in a contract for easy enforcement.

However, a monopolist who continuously provides such traditional incentives to manufacturers may violate antitrust law by exploiting its monopolistic position and excluding competitors or potential entrants. For instance, in early 2017, Qualcomm, one of the leading modem chip suppliers, was accused by FTC and Apple Inc., one smartphone manufacturer and one of Qualcomm's modem chip buyers, that its bundled rebate and loyalty discount program should violate Sherman Act Section Two. ${ }^{1}$ Specifically, the way Qualcomm delivered the program was unique - it bundled the selling of physical modem chips with the licensing of involved standard essential patents (SEPs). That is, if Apple desired to buy Qualcomm's chips, it had to acquire SEP licenses at a certain royalty rate with the chips altogether. ${ }^{2}$ Qualcomm would refund Apple a lump sum of money in return for Apple's commitment. Therefore, Apple asserted that it was induced to purchase modem chips from Qualcomm continuously and exclusively. ${ }^{3}$

This article focuses on analyzing reasons underlying Qualcomm's behavior in the real world. Why does Qualcomm insist on delivering the bundled rebate and loyalty discount program for Apple Inc., if they are likely to be illegal under antitrust law? To answer this question, this article is organized as follows. Section 2 reviews related literature in legal and business areas. Section 3 describes the legal disputes and the modem chip industry status quo that FTC and Apple Inc. have talked about in their complaints. Section 4 addresses the case law of antitrust regime, which lays the foundation of our model analysis in Section 5. We attempt to derive business incentives for Qualcomm to insist on implementing the bundled rebate and loyalty discount program regardless of legal risks. In detail, this article analyzes three different scenarios: the single-stage exhaustive contract setting, the single-stage nonexhaustive contract setting, and the two-stage exhaustive contract setting. We examine how patent licensing and quality improvement might affect Qualcomm's bundling rebate decisions. Section 6 summarizes some implications as to why Qualcomm insists on implementing its bundled rebate and loyalty discount program. We justify that the key business reason is that Qualcomm would like to prevent itself from future fierce competition with potential competitors who improve their product quality significantly. Finally, Section 7 concludes this article.

\footnotetext{
${ }^{1}$ See Apple REDACTED First Amended Complaint (2017). Available at: https://regmedia.co.uk/2017/06/20 /applevqualcomm620complaint.pdf

2 Id.

${ }^{3}$ Id.
} 


\section{Literature Review}

\subsection{Legal Literature}

Bundled rebate has been widely discussed by antitrust scholars. For instance, government agencies and the courts argue that firms tie because of their desires to leverage monopoly power to another market. This is so called leverage theory. ${ }^{4}$ By contrast, Chicago theorists address "single monopoly profit" theory against the "leverage theory." This theory addresses that a monopolist with one product cannot increase its profits by tying itself into another monopolistic market with different products (Director and Levi 1956; Bowman 1957; Bork 1978; Posner 1978; Easterbrook and Posner 1981; Posner 2001). These products have to be complementary; otherwise, there is no reason to tie.

Furthermore, some scholars investigate the benefits of bundling and tying. For instance, by providing bundled products or services, suppliers or sellers can have economies of scope to reduce costs of sales (Sagi 2014) and can reduce the buyers' transaction and information costs (Crane 2012). Moreover, Stigler (1968) argues that firms can have more surplus due to different product valuations of consumers by tying through price discrimination. Bowman (1957) argue that seller or suppler can charge more by tying in the presence of greater demand for complementary products. Whinston (1990) used a game-theoretic model to argue that a monopolist committed to tie its product with another can foreclose an efficient competitor in another market from the entry. Furthermore, Elhauge (2009) argues that the single monopoly profit theory raised by Chicago theorists should not be per se legal since the relaxation of its assumptions will cause power effects and foreclosure share effects. Power effect might cause intraproduct price discrimination, interproduct price discrimination, and the extraction of individual consumer surplus. Foreclosure share effect might increase the market power of a monopolist in the tying or tied market. Both effects will reduce consumer welfare in result.

On the contrary, Evans and Salinger (2005) first argue the flaws of Whinston's (1990) model. They address that the foreclosure theory fails to consider the efficiency of bundling in the competitive market and the guidance to antitrust agencies and the courts. They propose their cost-based model to defend the legality of bundling or tying. According to their model, the bundling would occur if the firm cannot cover the fixed costs of separate goods due to insufficient demand. Furthermore, the firm also has incentives to bundle even if there is sufficient demand and moderate fixed cost for the separate goods because bundled goods are cheap to customers.

The aforementioned studies have a large influence on the antitrust academia. However, most scholars do not consider FRAND commitment in their contexts. Rather, they focus only on the economic rationales of tying or bundled discounts behind the procompetitive or anticompetitive effects. Until now, only a few scholars discuss the issue of the FRAND commitment intertwined with bundled discount or tying.

For instance, Wong-Ervin et al. (2016) argue that tying SEPs with non-SEPs may not violate antitrust law because of the following reasons. First, the US antitrust law does not punish a monopolist that lawfully extracts surplus from consumer. Rather, the US antitrust law punishes the monopolist when unlawfully acquiring a monopolistic position, which is exclusionary or predatory. Therefore, even though tying SEPs and non-SEP may result in higher prices and may breach the FRAND commitment, SEP holders should not be penalized under

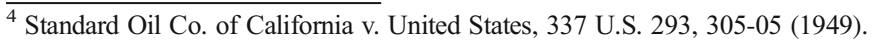


antitrust law since this is the contract law issue, not the antitrust law. Second, although tying can possibly harm the market, the authors urge that there are many efficiency justifications for having tying such as the ease of the cost of licensing and negotiation and the benefits of patent pooling. On the contrary, Melamed and Shapiro (2017) argue that tying SEPs with non-SEPs may violate Sherman Act Section One because SEP holders can have more considerations and royalties with tying. Thus, SEP holders would not only violate FRAND commitment but also extend its market power by allocating the considerations.

Hovenkamp (2017) discusses whether FRAND commitment should expand to its scope from SEPs to so-called collateral input under vertically integrated-practice situation. The author proposes that the scope of the FRAND commitment should be expanded to collateral input because tying can let the firm evade the SEP price, which is under the control of FRAND commitment, by overcharging the unregulated good, namely modem chips in this context. As for this argument, the author reasons that tying arrangement can naturally foreclose rivals' sales through the combination of loyalty discounting and rebate-pricing programs, even though the SEP holders cannot refuse to license its SEPs to rivals under the FRAND commitment.

In terms of loyalty discounting, rivals will be excluded if the loyalty discount is huge enough. Under the FRAND commitment context, the author argues that if the SEP holders tie its products and SEP licenses together with the loyalty discount, they can raise the licensing royalties and the loyalty discount simultaneously. In this way, the SEP holders will not violate FRAND commitment while excluding rivals since the total amount of the price is still under FRAND commitment. As regards the rebate-pricing behavior, the author addresses that the SEP holders can manipulate the patent litigation system about how the courts calculate a reasonable royalty. By exercising rebate pricing, SEP holders can conceal the loyalty discounting arrangement by means of "royalty gamesmanship." As a result, rivals facing significant supply costs might be excluded.

In detail, there are two logic reasonings behind these arguments. First, since the courts usually rely on "comparable licenses" to calculate reasonable royalties, SEP holders know that their license agreements might be referred to by the courts in the future. Thus, it is reasonable for the SEP holders to set the final established royalties significantly. Second, constrained by FRAND commitment, SEP holders would like to use the "independent" rebate agreement and the SEP licensing agreements with higher royalty rates. This is called "royalty gamesmanship" in the article. The courts might mistakenly think that the licensing agreements do not violate FRAND commitment since the final amount of price is within the scope of the commitment; then, these agreements are adopted as "comparable licenses." As a consequence, the rivals, which are also the licensees under the FRAND commitment, will have to bear a higher cost of licensing.

\subsection{Business Literature}

Physical products and intangible patents are bundled in the modem chip transactions between Qualcomm and Apple. Therefore, this paper is related to the studies on bundled contracts in the literature. There are voluminous studies on contract design for commodity bundling (see Kobayashi 2005 for a review). In contrast to the existing literature, this article studies the pricing decision of modem chips bundled with patents used in these chips. Patents are traded in a totally different way from physical products, with royalties not unit prices charged to buyers. As a result, the bundling of products and patents is different from that of two or multiple products. In this paper, we study the bundled program in consideration of different patent licensing strategies. 
With patents involved in the modem chip transactions, this research is also related to the literature on patent licensing. Llobet and Padilla (2016) analyze the patent licensing decision of an upstream innovator that licenses its technology to a pure downstream producer and find that ad valorem royalties favor the innovator, whereas per unit royalties tend to benefit the producer. Chen et al. (2017) consider downstream competition in their paper and study the patent licensing problem between a component supplier and two duopoly manufacturers. They demonstrate that the component supplier prefers to implement the product-based licensing strategy while the manufacturers' preferences depend on how effectively they produce products. Yang et al. (2019) investigate how a patent-holding supplier should license its technology to a potential rival in the presence of supply disruption risks. The results show that the optimal licensing strategy is dependent on the downstream manufacturer's sourcing decision and the reliability of the suppliers' productions. Most existing studies on patent licensing strategies do not address the licensing problem together with a bundled rebate program. Differently, our study will focus on the bundled rebate program in the business of product selling and patent licensing.

The last stream of business literature relevant to our study focuses on exclusive contracts, including rebate programs. DeGraba (2013) shows that a dominant supplier can pay downstream firms for exclusivity, allowing him to maintain supra-competitive input prices, even when a small rival that is more efficient at serving some portion of the market can make exclusive offers. Similar studies are focused on only one product, let alone take bundled product selling and patent licensing into account. Graf (2014) studies exclusive or partially exclusive rebate contracts in the pharmaceutical industry and finds that manufacturers might prefer some rebate contracts, but no rebate form lowers costs for consumers or improves total welfare. Hovenkamp (2017) indicates that a SEP holder could use loyalty-contingent rebates to stimulate purchase of inputs and patents from the SEP holder exclusively. Nevertheless, he does not address this problem with an economic model. In this paper, we introduce a stylized game-theoretical model between a patent holder who is also a component supplier, a rival supplier, and a monopoly manufacturer and study the rebate offer of the patent holder.

\section{Modem Chip Industry and Qualcomm's Alleged Behavior}

In this part, we will first introduce the modem chip industry and major modem chip suppliers in this industry. Next, we will have a look at how Qualcomm has become one of the leading players in the cellular network and modem chip industry. Second, we will briefly address what FTC and Apple assert in their complaint. This part lays the foundation of our models in Section 5 .

\subsection{Introduction of Modem Chip Industry and Qualcomm Company}

According to Strategy Analytics' report, Qualcomm, MediaTek, Samsung LSI, Huawei, and Spreadtrum are the top-five revenue share spots in the global 4G (LTE) modem chip market in 2017. ${ }^{5}$ Qualcomm, as a market leader, increased its revenue share to $53 \%$ in 2017. By contrast,

\footnotetext{
${ }^{5}$ Baseband Market Share Tracker 2017: Intel, HiSilicon and Samsung Register double-digit LTE Shipment Growth, Baseband Market Share Tracker 2017: Intel, HiSilicon and Samsung Register double-digit LTE Shipment Growth (2018), https://www.strategyanalytics.com/access-services/components/handsetcomponents/market-data/report-detail/baseband-market-share-tracker-2017-intel-hisilicon-and-samsung-registerdouble-digit-lte-shipment-growth (last visited November 18, 2018).
} 
MediaTek had a $16 \%$ revenue share and Samsung LSI had 12\%. However, according to FTC's complaint, only Qualcomm, Samsung, Intel, and Huawei supply "premium LTE modem chips" to giant smartphone manufacturers such as Apple and Samsung. Therefore, if we focus on premium LTE modem chips, Qualcomm has dominated the market with a share over $80 \%$.

Founded in 1985, Qualcomm has been designing, developing, and improving cellular communication systems, networks, and products that have transformed the way the world communicates. It has contributed numerous innovations used in almost every modern cell phone by inventing fundamental technologies for $2 \mathrm{G}, 3 \mathrm{G}$, and $4 \mathrm{G}$ cellular communications and leading the industry to $5 \mathrm{G}$. For instance, Qualcomm transformed the cellular industry by introducing code-division multiple access (CDMA). CDMA was initially introduced as a groundbreaking $2 \mathrm{G}$ cellular technology that vastly improved the capacity of cellular networks and the quality of cellular service by allowing a large number of users to communicate simultaneously while sharing the same frequency channel. Moreover, Qualcomm's innovative solutions formed the basis of 3G. In 2006, Qualcomm acquired Flarion Technologies and combined its innovations and research efforts with its own. Using this technology, Qualcomm pioneered the application of orthogonal frequency-division multiple access (OFDMA) and single-carrier frequency-division multiple access (SC-FDMA) to cellular systems, which eventually became the basis for the $4 \mathrm{G}$ standards known broadly as long-term evolution (LTE). These innovations once again expanded network capacity and vastly boosted data speeds well beyond the $3 \mathrm{G}$ systems.

Over the past three decades, Qualcomm's R\&D investment has amounted to more than $\$ 40$ billion. From 2010 to 2016, Qualcomm typically spent more than $20 \%$ of its revenue per year R\&D. Nearly 20,000 engineers work on expanding the boundaries of cellular and other mobile technologies. Qualcomm's patent portfolio currently includes more than 130,000 issued patents and patent applications worldwide. As a result of the continuous commitment to innovation, Qualcomm's technologies facilitate the cellular ecosystem that allows smartphones to send and receive vast amounts of data and voice communications at rapid speeds, seamlessly and reliably, from anywhere within reach of a cellular network. Thus, its contributions to the modem chip industry are necessary for the entire cellular network to function.

Rather than privatize its core inventions, Qualcomm chose to patent its inventions, contribute them to standards bodies, and voluntarily license them to cellular device manufacturers. As a result of this, companies are able to create products and experiences that consumers enjoy today. Qualcomm, through its licensing division, QTL, now has license agreements with hundreds of companies covering $3 \mathrm{G}$ and $4 \mathrm{G}$ cellular technologies and products. Furthermore, separated from its licensing business, Qualcomm's subsidiary, Qualcomm Technologies Inc. (QTI), designs industry-leading components, such as chipsets and associated software, sold for use in the manufacture and operation of cellular devices. QTI has consistently been the leader in bringing to market cutting-edge chipsets - sometimes years ahead of the competition.

Finally, when supplying modem chips to its customers, companies such as Qualcomm and Samsung need to consider patent licensing as well. As we introduced earlier, Qualcomm's broad patent portfolios are widespread among the cellular network ecosystem. Some of its patent portfolios that cover standard technologies for 2G, 3G, and 4G (LTE) are called standard essential patents (SEPs), and they are priced and licensed separately from the pricing and sale of QTI's components. A Qualcomm licensee pays the same royalty to Qualcomm for a patent portfolio license no matter whether its licensed cellular devices are comprised of components supplied by QTI's subsidiary, the licensee itself, or another QTI competitor. However, Qualcomm has to follow the FRAND commitment when setting patent royalties in order to 
popularize the standard. The FRAND commitment is important in this paper because it serves as one of assumptions to set up patent royalty in our model.

\subsection{Qualcomm's Alleged Behavior}

In early 2017, both FTC and Qualcomm's customer, Apple, sued Qualcomm for violating antitrust law. As claimed in the complaints, at some time before 2006, Qualcomm secretly asked Apple's original equipment manufacturers (OEMs) to pay higher SEP royalty fees with the cost trickling down to Apple. If OEMs refused to pay, Qualcomm would not supply its premium modem chips to them. This is so called no license, no chips policy. Qualcomm's request was included in several nondisclosure agreements with the OEMs. Therefore, Apple could not assure the scope of SEPs and the reasonable price for the SEPs. ${ }^{6}$

Because Apple had been charged for a higher SEP royalty fee indirectly for couple of years, the company desired to reduce the amount of the royalties. Apple negotiated with Qualcomm directly, and in response, Qualcomm agreed to supply them with its premium modem chips. Apple had to accept two conditions in exchange for stead supply from Qualcomm. First, Apple had to exclusively use Qualcomm's modem chips in its smartphones. In return, Qualcomm would refund a fixed amount of rebate to lower the total amount of SEP royalties. This condition, as in the complaint, is also called "bundled rebate program". Second, Apple cannot sue or induce any kind of lawsuits against Qualcomm.

These conditions can be seen in several agreements between Qualcomm and Apple. For instance, the parties' Business Cooperation and Patent Agreement (BCPA) expressly calculates a series of quarterly payments to Apple (BCP Payments), as a cap on the royalties that Apple pays to Qualcomm, setting the amount of the payment at a lump sum that effectively reduced Apple's per-device royalty payment. In First Amendment to Transition Agreement (FATA), Qualcomm paid Apple if it exclusively uses Qualcomm baseband processor chipsets. As with the Transition Agreement (TA), a portion of the payments made by Qualcomm pursuant to that FATA were understood by the parties to be a form of royalty relief, conditioned on Apple's agreement to deal with Qualcomm exclusively. Because of this behavior, Apple and FTC finally filed lawsuit against Qualcomm for alleged violation of the Sherman Act Section Two - monopolization by manipulating bundled rebate and loyalty discount programs.

\section{Cases Related to Bundled Rebate}

Confronted with the issue of the bundled rebate, Federal Court judges apply Sherman Act Section One and Two to analyze the cases. The Sherman Act states:

Every contract, combination in the form of trust or otherwise, or conspiracy, in restraint of trade or commerce among the several States, or with foreign nations, is declared to be illegal. Every person who shall make any contract or engage in any combination or conspiracy hereby declared to be illegal shall be deemed guilty of a felony, and, on conviction thereof, shall be punished by fine not exceeding $\$ 100,000,000$ if a

\footnotetext{
${ }^{6}$ Apple Amended Complaint (2017). Available at: https://regmedia.co.uk/2017/06/20/applevqualcomm620 complaint.pdf
} 
corporation, or, if any other person, $\$ 1,000,000$, or by imprisonment not exceeding 10 years, or by both said punishments, in the discretion of the court. ${ }^{7}$

Every person who shall monopolize, or attempt to monopolize, or combine or conspire with any other person or persons, to monopolize any part of the trade or commerce among the several States, or with foreign nations, shall be deemed guilty of a felony, and, on conviction thereof, shall be punished by fine not exceeding $\$ 100,000,000$ if a corporation, or, if any other person, $\$ 1,000,000$, or by imprisonment not exceeding 10 years, or by both said punishments, in the discretion of the court. ${ }^{8}$

To establish a Section Two violation, plaintiffs must show that (1) the defendant possessed monopoly power in the relevant market and (2) the defendant willfully acquired or maintained this monopoly power by anticompetitive conduct as opposed to gaining that power as a result "of a superior product, business acumen, or historical accident." ${ }^{9}$ However, different judges from different circuits have treated bundled rebate programs differently. For instance, while some judges interpret bundled rebate program under an exclusive dealing regime, other judges treat bundled rebate as a type of tying. The reasoning that judges analyzed in the following two cases will become our assumptions of the model in Section 5.

\subsection{LePage's Inc. v. 3M, 324 F.3d 141 (3d Cir. 2003)}

3M manufactures Scotch tape and it dominated the US transparent tape market with a market share of above $90 \%$ in the early 1900s. LePage's, on the other hand, decided to sell "second brand" and private label transparent tapes, i.e., tape sold under the retailer's name rather than under the name of the manufacturer during the 1980s. LePage's brought this antitrust action for Sherman Act Section 2 asserting that 3M used its monopoly to gain a competitive advantage through the use of a multi-tiered "bundled rebate" structure. $3 \mathrm{M}$ offered many of LePage's major customers substantial rebates to induce them to eliminate or reduce their purchases of tapes from LePage's. In addition, $3 \mathrm{M}$ offered discounts to certain customers conditional on purchases spanning six diverse product lines. ${ }^{10}$ The amount of the rebate was linked to the number of product lines in which targets were met. If a customer failed to meet the target for any one product, it would lose the rebate across the line.

The Court held that 3M's rebate programs violated the Sherman Act Section 2 because the rebates and discounts to Kmart, Staples, Sam's Club, and National Office Buyers were designed to induce buyers not to do business with LePage. For instance, Kmart switched to $3 \mathrm{M}$ following 3M's offer of a $\$ 1$ million "growth" reward, and Staples was offered an extra $1 \%$ bonus rebate if it switched its business to $3 \mathrm{M}$. Furthermore, the Court found that the foreclosure caused by exclusive dealing practices was magnified by 3M's discount practices, as some of 3M's rebates were "all-or-nothing" discounts, leading 3M's customers to maximize their discounts by dealing exclusively with $3 \mathrm{M}$. Only by dealing exclusively with $3 \mathrm{M}$ in as many product lines as possible could customers enjoy the substantial discounts and avoid being severe penalization for failing to meet their quotas. As a result, LePage's lost a

\footnotetext{
${ }^{7}$ See 15 U.S.C $\$ 1$.

${ }^{8}$ See 15 U.S.C $\$ 2$.

${ }^{9}$ See United States v. Grinnell Corp., 384 U.S. 563 (1966).

${ }^{10}$ The product lines covered by the rebate program were as follows: Health Care Products, Home Care Products, Home Improvement Products, Stationery Products (including transparent tape), Retail Auto Products, and Leisure Time.
} 
proportional amount of sales and a large number of customers, such as Kmart, Staples, American Drugstores, Office Max, and Sam's Club. Other large customers, like Walmart, drastically cut back their purchases.

Considering 3M's bundled rebate program had an exclusive effect against its competitor and violated Sherman Act Section Two, which is similar to the Qualcomm's situation, we will assume that Qualcomm's bundled rebate program would have an exclusive effect in our model.

\subsection{Jefferson Parish Hosp. Dist. v. Hyde, 466 U.S. 2 (1984)}

Jefferson Hospital entered into an "Anesthesiology Agreement" with Roux \& Associates. The contract provided that any anesthesiologist designated by Roux would be admitted to the hospital's medical staff, and in exchange, the hospital would provide the space, equipment, maintenance, drugs, and personnel necessary to operate the anesthesiology department. Moreover, the hospital agreed to limit the use of its anesthesia department solely to Roux \& Associates. Edwin H. Hyde, a board-certified anesthesiologist, applied for a job at Jefferson Hospital, but he was rejected by the hospital board because of the agreement with Roux \& Associates. Hyde filed suit against Jefferson Hospital for the violation of Sherman Act Section One.

The Justices in the opinion elaborated the rule for a tying case. First, a firm producing tying product has monopoly power. Second, there must be a substantial threat that the tying seller will acquire market power in the tied market. Third, there must be coherent basis for treating the tying and tied products as distinct. For products to be treated as distinct, the tied product must be one that some consumers might wish to purchase separately without also purchasing the tying product. Finally, the court would balance between the economic benefit and the economic harm of the accused tying arrangement. In applying the rule above, the Court held that the tying arrangement by the Jefferson Hospital is lawful. Interestingly, the Court only relied on the market share and reasoned that only $30 \%$ of residents would go to the Jefferson Hospital. Thus, there is no indication that the hospital had market power at that time. Because there was no market power to produce tying product, it was impossible to foreclose its competitors.

Here, we understand that the analysis of tying needs to consider whether the tying company has monopoly power or not. Based on the introduction of Qualcomm company, we assume that Qualcomm takes a monopolistic position in the modem chip industry in our model.

\section{Model Analysis}

We model the business between Qualcomm and Apple in this section and investigate economic explanations for the bundled rebate program provided by Qualcomm to Apple when facing a potential competitor. Though Intel announced to exit $5 \mathrm{G}$ smartphone modem business on April 16, 2019, ${ }^{11}$ it still provides premium modem chips to prevailing $4 \mathrm{G}$ smartphones and once cooperated with Apple. ${ }^{12}$ Therefore, we take Intel as an example of Qualcomm's competitors in this paper.

\footnotetext{
${ }^{11}$ See https://newsroom.intel.com/news-releases/intel-modem-statement/ (last visited May 11, 2019)

${ }^{12} \mathrm{See}$ https://www.marketwatch.com/story/qualcomm-claims-wireless-dominance-over-intel-and-apple-201807-23 (last visited November 19, 2018).
} 
In the modem chip industry, Apple is a representative buyer while Qualcomm is a dominant seller. Together with another chipset supplier, Intel, these companies constitute a typical twoechelon supply chain. In this setting, Apple is the monopoly manufacturer, though in real cases, it does not produce any product on its own. Qualcomm and Intel are competing suppliers, with Qualcomm dominating Intel with evidently higher-quality products currently. In addition, Qualcomm is almost a monopoly in licensing patents employed in modem chips. It does not sell exhaustive licenses to rival chipmakers (Hovenkamp 2017). As a consequence, Apple pays Qualcomm for patent licensing no matter which supplier it procures modem chips from. Though in reality, there are many more companies participating in this industry, the case we introduce here is an epitome of the modem business in reality, given the dominant positions of Apple as one of the leading smartphone brands and Qualcomm as a chipset provider and patent owner.

Given patents involved are bundled with modem chips, there are different patent licensing schemes. To model complex activities between these three parties, we analyze three scenarios here: a single-stage exhaustive contract, a single-stage non-exhaustive contract, and a twostage exhaustive contract. In exhaustive contracts, Qualcomm charges Apple royalties according to patents used in chipsets sold, i.e., SSU. In non-exhaustive contracts, the royalties are calculated on the basis of the entire market value of end products, i.e., EMV. We suppose Qualcomm supply better modem chips than Intel in the first stage, which is also the real case in recent years. In the second stage, Intel improves its product quality to the same level as Qualcomm and becomes a threatening rival.

We assume that both the manufacturer and two suppliers are risk-neutral and maximize their expected profits. We suppose a sequential game between these roles with suppliers being the game leader and Apple being the follower or the price-taker. The whole game proceeds as shown in Fig. 1. For the remainder of our study, we use $\Pi$ to denote the manufacturer's and suppliers' expected profits and subscripts A, Q, and I to denote three market members, i.e., Apple, Qualcomm, and Intel, respectively.

We assume Qualcomm's chipsets with higher quality $q_{\mathrm{Q}}$ and higher cost $\mathrm{c}_{\mathrm{Q}}$, while Intel's quality and cost in the first stage are denoted by $q_{\mathrm{I}}$ and $c_{\mathrm{I}}$. Here, $q_{\mathrm{Q}}>q_{\mathrm{I}}$ and $c_{\mathrm{Q}}>c_{\mathrm{I}}$. The market demand of end products is assumed to be deterministic, and it is a linear function of the retail price and product quality, i.e., $d=a-b p+\gamma q$, where $a$ is the potential market size and $b$ and $\gamma$ are the elasticities of demand to price and quality, respectively. To avoid the triviality of our model, we assume the potential demand satisfies $a \geq \max \left[b c_{\mathrm{Q}}-\gamma q_{\mathrm{Q}}, b c_{\mathrm{I}}-\gamma q_{\mathrm{I}}\right]$. Let $\left(w_{\mathrm{Q}}, \alpha\right)$

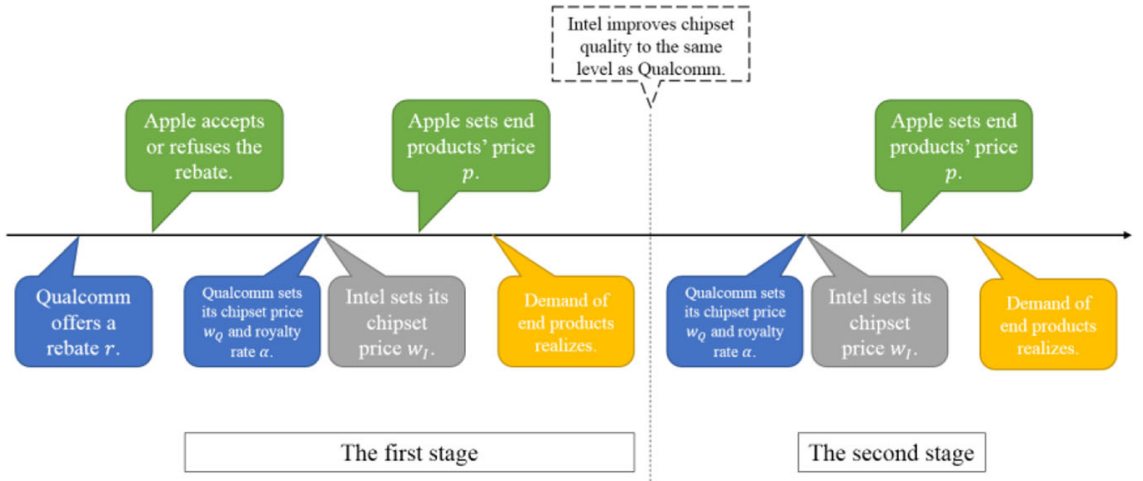

Fig. 1 Sequence of events 
denote the contract Qualcomm provides to Apple, where $w_{\mathrm{Q}}$ is the unit chipset price and $\alpha$ is the royalty rate. We suppose that $\alpha \in[0, \bar{\alpha}]$ with $\bar{\alpha}<1$, given there are industry regulations, for example, FRAND terms. Differently, if Apple procures from Intel, the contract provided by Intel will be a simple wholesale price contract, i.e., $w_{\mathrm{I}}$. Besides, we define a lump-sum rebate provided by Qualcomm to exclude other potential rivals as alleged by Apple, denoted by $r$. In every scenario, we compare two specific situations. In the first situation, Apple accepts the exclusive rebate and signs a contract with Qualcomm, while in the second one, Apple refuses the rebate and waits for a better opportunity lying in the competition between Qualcomm and Intel.

\subsection{Single-Stage Exhaustive Contract}

In an exhaustive setting, we suppose all relevant patents are exhausted once chipsets are sold. Therefore, Apple only needs to pay chipset costs. This is equivalent to the case that Apple pays patent royalties to Qualcomm according SSUs in purchased chipsets. In this case, Apple needs to pay $w_{\mathrm{q}}+\alpha w_{\mathrm{q}}=w_{\mathrm{q}}^{\prime}$ for per unit chipset. After this clarification, we present the models and analyze whether it is reasonable for Qualcomm to offer an exclusive rebate to target Apple and exclude Intel.

\subsubsection{Apple Signs the Rebate Contract}

If Apple accepts the rebate provided by Qualcomm, then Apple cannot trade with Intel in the future, or it has to pay a large amount of default fines to Qualcomm. As a consequence, Intel is excluded from the business. Therefore, we come up with the following profit functions of Qualcomm and Apple.

$$
\left\{\begin{array}{l}
\Pi_{\mathrm{Q}}=\left(w_{\mathrm{Q}}-c_{\mathrm{Q}}\right)\left(a-b p+\gamma q_{\mathrm{Q}}\right)-r \\
\Pi_{\mathrm{A}}=\left(p-w_{\mathrm{Q}}\right)\left(a-b p+\gamma q_{\mathrm{Q}}\right)+r
\end{array}\right.
$$

By backward induction, we find the equilibrium strategies for both parties summarized as below.

$$
\left\{\begin{array}{c}
w_{Q}^{*}=\frac{a+\gamma q_{\mathrm{Q}}+b c_{\mathrm{Q}}}{2 b} \\
p^{*}=\frac{3\left(a+\gamma q_{\mathrm{Q}}\right)+b c_{\mathrm{Q}}}{4 b} \\
\Pi_{\mathrm{Q}}^{*}=\frac{\left(a+\gamma q_{\mathrm{Q}}-b c_{\mathrm{Q}}\right)^{2}}{8 b}-r \\
\Pi_{\mathrm{A}}^{*}=\frac{\left(a+\gamma q_{\mathrm{Q}}-b c_{\mathrm{Q}}\right)^{2}}{16 b}+r
\end{array}\right.
$$

To be mentioned here, ignoring the rebate difference, Qualcomm earns a higher profit than Apple owing to its leading role in the sequential game.

\subsubsection{Apple Does Not Sign the Rebate Contract}

If Apple refuses to sign the rebate contract offered by Qualcomm, then Intel's entry will make a big difference in the market. We can estimate that Apple will benefit a lot from the price war 
between Qualcomm and Intel. In spite of its quality advantage, Qualcomm still suffers some loss in this situation. We formulate their profit functions as below, respectively.

$$
\left\{\begin{array}{c}
\Pi_{\mathrm{Q}}=\max \left[\left(w_{\mathrm{Q}}-c_{\mathrm{Q}}\right)\left(a-b p+\gamma q_{\mathrm{Q}}\right), 0\right] \\
\Pi_{\mathrm{I}}=\max \left[\left(w_{\mathrm{I}}-c_{\mathrm{I}}\right)\left(a-b p+\gamma q_{\mathrm{I}}\right), 0\right] \\
\Pi_{\mathrm{A}}=\max \left[\left(p_{\mathrm{Q}}-w_{\mathrm{Q}}\right)\left(a-b p_{Q}+\gamma q_{\mathrm{Q}}\right),\left(p_{\mathrm{I}}-w_{\mathrm{I}}\right)\left(a-b p_{\mathrm{I}}+\gamma q_{\mathrm{I}}\right)\right]
\end{array}\right.
$$

Let us have a look at Apple's possible profit at first. No matter which supplier it chooses to procure from, its best response is $p_{\mathrm{i}}=\frac{a+\gamma q_{\mathrm{i}}+b w_{\mathrm{i}}}{2 b}, i \in\{\mathrm{Q}, \mathrm{I}\}$. As a result, Apple's optimal profit is given by

$$
\Pi_{\mathrm{A}}^{*}=\max \left[\frac{\left(a+\gamma q_{\mathrm{Q}}-b w_{\mathrm{Q}}\right)^{2}}{4 b}, \frac{\left(a+\gamma q_{\mathrm{I}}-\mathrm{b} w_{\mathrm{I}}\right)^{2}}{4 b}\right]
$$

To avoid losing in the price war, both Qualcomm and Intel will provide as low as possible prices to Apple under the premise that they can still profit. We obtain the wholesale prices when Apple gets the same profit no matter from Qualcomm or from Intel. That is, $\gamma\left(q_{\mathrm{Q}}-q_{\mathrm{I}}\right)=$ $b\left(w_{\mathrm{Q}}-w_{\mathrm{I}}\right)$. Let $m_{\mathrm{Q}}=a+\gamma q_{\mathrm{Q}}-b c_{\mathrm{Q}}$ and $m_{\mathrm{I}}=a+\gamma q_{\mathrm{I}}-b c_{\mathrm{I}}$, then $m_{\mathrm{Q}}$ (or $m_{\mathrm{I}}$ ) is the maximal possible demand when Qualcomm (or Intel) is the only supplier. Since both suppliers can only accept a price no lower than their production cost, we get the equilibrium outcome in different cases as follows.

Case 1: If $m_{\mathrm{Q}} \geq m_{\mathrm{I}}$, Apple chooses Qualcomm and

$$
\left\{\begin{array}{c}
w_{\mathrm{Q}}^{*}=\frac{b c_{\mathrm{I}}+\gamma\left(q_{\mathrm{Q}}-q_{\mathrm{I}}\right)}{b} \\
p^{*}=\frac{a+b c_{\mathrm{I}}+\gamma\left(2 q_{\mathrm{Q}}-q_{\mathrm{I}}\right)}{2 b} \\
\Pi_{\mathrm{Q}}^{*}=\frac{\left(a+\gamma q_{\mathrm{I}}-b c_{\mathrm{I}}\right)\left[\gamma\left(q_{\mathrm{Q}}-q_{\mathrm{I}}\right)-b\left(c_{\mathrm{Q}}-c_{\mathrm{I}}\right)\right]}{2 b} \\
\Pi_{\mathrm{I}}^{*}=0 \\
\Pi_{\mathrm{A}}^{*}=\frac{\left(a+\gamma q_{\mathrm{I}}-b c_{\mathrm{I}}\right)^{2}}{4 b}
\end{array}\right.
$$

Case 2: If $m_{\mathrm{Q}}<m_{\mathrm{I}}$, Apple chooses Intel and

$$
\left\{\begin{array}{c}
w_{\mathrm{Q}}^{*}=\frac{b c_{\mathrm{Q}}-\gamma\left(q_{\mathrm{Q}}-q_{\mathrm{I}}\right)}{b} \\
p^{*}=\frac{a+b c_{\mathrm{Q}}+\gamma\left(2 q_{\mathrm{I}}-q_{\mathrm{Q}}\right)}{2 b} \\
\Pi_{\mathrm{I}}^{*}=\frac{\left(a+\gamma q_{\mathrm{Q}}-b c_{\mathrm{Q}}\right)\left[b\left(c_{\mathrm{Q}}-c_{\mathrm{I}}\right)-\gamma\left(q_{\mathrm{Q}}-q_{\mathrm{I}}\right)\right]}{2 b} \\
\Pi_{\mathrm{A}}^{*}=\frac{\left(a+\gamma q_{\mathrm{Q}}-b c_{\mathrm{Q}}\right)^{2}}{4 b}
\end{array}\right.
$$


The above results indicate that when Qualcomm's quality advantage dominates its cost disadvantage when compared with Intel, i.e., $\gamma\left(q_{\mathrm{Q}}-q_{\mathrm{I}}\right) \geq b\left(c_{\mathrm{Q}}-c_{\mathrm{I}}\right)$ or $m_{\mathrm{Q}} \geq m_{\mathrm{I}}$, it is the winner in the competition; while when its quality advantage is relatively weaker, i.e., $m_{\mathrm{Q}}<m_{\mathrm{I}}$, it loses the business with Apple.

\subsubsection{Comparative Analysis}

To exclude Intel from the price competition, Qualcomm must offer a sufficiently attractive rebate to Apple. Comparing the equilibrium in the previous two situations, we find that the rebate should be no lower than $\frac{3\left(a+\gamma q_{\mathrm{Q}}-b c_{\mathrm{Q}}\right)^{2}}{16 b}$ if $m_{\mathrm{Q}}<m_{\mathrm{I}}$, which brings about a negative profit to Qualcomm in Eq. (1.2), though. Therefore, Qualcomm has no incentive to offer a rebate to Apple if its quality advantage is dominated by Intel's cost advantage.

If $m_{\mathrm{Q}} \geq m_{\mathrm{I}}$, the condition that $r \geq\left(\frac{4\left(a+m_{\mathrm{I}}\right)^{2}-\left(a+m_{\mathrm{Q}}\right)^{2}}{16 b}\right)^{+}$must be satisfied if Qualcomm would like Apple to sign the exclusive rebate contract. Then, we find that Qualcomm will not offer this rebate if $m_{\mathrm{Q}}<2 m_{\mathrm{I}}$. And it offers the rebate only if $m_{\mathrm{Q}} \geq 2 m_{\mathrm{I}}$. Moreover, Apple will accept any rebate offered by Qualcomm in this case, because it already gets a no lower profit in the market. Therefore, we come up with the following proposition.

Proposition 1 In a single-stage exhaustive contract setting, it is economically reasonable for Qualcomm to provide an exclusive rebate contract to Apple if and only if $m_{\mathrm{Q}} \geq 2 m_{\mathrm{I}}$, and the optimal rebate could be $\epsilon$, where $\epsilon$ is positive but very small.

Overall, Qualcomm cannot suffer the loss when its quality advantage is not enough obvious, whereas Apple is absolutely willing to procure from Qualcomm when its quality advantage is very dominant. Therefore, whether it has an advantage over Intel or not, it is unwise and unnecessary for Qualcomm to offer a rebate contract to Apple if the bundled patents are exhaustive.

\subsection{Single-Stage Non-Exhaustive Contract}

In a non-exhaustive contract, Apple needs to pay patent royalties along with chipset costs. As a result, Qualcomm can earn revenue from royalties even when it is not Apple's chipset supplier. Again, we will at first analyze separate situations and then compare them with each other.

\subsubsection{Apple Signs the Rebate Contract}

If Apple accepts the rebate contract, then Qualcomm will actually become the only supplier in the market. We get the following profit functions for each party.

$$
\left\{\begin{array}{l}
\Pi_{\mathrm{Q}}=\left(w_{\mathrm{Q}}-c_{\mathrm{Q}}+\alpha p\right)\left(a-b p+\gamma q_{\mathrm{Q}}\right)-r \\
\Pi_{\mathrm{A}}=\left((1-\alpha) p-w_{\mathrm{Q}}\right)\left(a-b p+\gamma q_{\mathrm{Q}}\right)+r
\end{array}\right.
$$


The equilibrium outcome is derived and summarized as below.

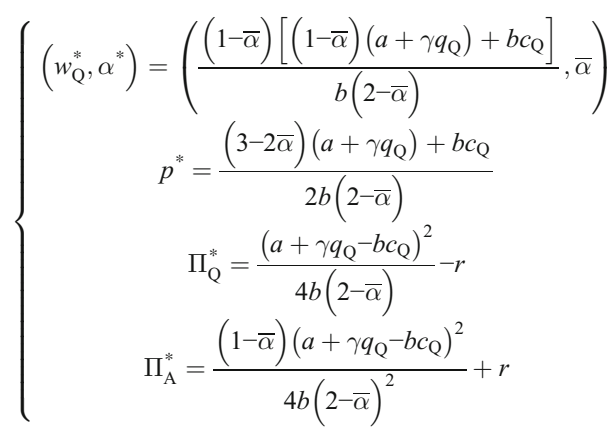

To guarantee the existence of the above equilibrium, we put forward a stricter assumption that $a \geq\left(b c_{\mathrm{Q}}-\gamma q_{\mathrm{Q}}\right) /(1-\bar{\alpha})^{2}$.

\subsubsection{Apple Does Not Sign the Rebate Contract}

If Apple rejects the exclusive rebate, then Qualcomm has no choice but to face the competition from Intel. If Apple chooses Qualcomm finally, their respective profits are formulated as below.

$$
\left\{\begin{array}{c}
\Pi_{\mathrm{Q}}=\left(w_{\mathrm{Q}}-c_{\mathrm{Q}}+\alpha p_{\mathrm{Q}}\right)\left(a-b p_{\mathrm{Q}}+\gamma q_{\mathrm{Q}}\right) \\
\Pi_{\mathrm{I}}=0 \# \# \# \\
\Pi_{\mathrm{A}}=\left((1-\alpha) p_{\mathrm{Q}}-w_{\mathrm{Q}}\right)\left(a-b p_{\mathrm{Q}}+\gamma q_{\mathrm{Q}}\right)
\end{array}\right.
$$

Instead, if Apple chooses Intel, their profit functions are different.

$$
\left\{\begin{array}{c}
\Pi_{\mathrm{Q}}=\alpha p_{\mathrm{I}}\left(a-b p_{\mathrm{I}}+\gamma q_{\mathrm{I}}\right) \\
\Pi_{\mathrm{I}}=\left(w_{\mathrm{I}}-c_{\mathrm{I}}\right)\left(a-b p_{\mathrm{I}}+\gamma q_{\mathrm{I}}\right) \\
\Pi_{\mathrm{A}}=\left((1-\alpha) p_{\mathrm{I}}-w_{\mathrm{I}}\right)\left(a-b p_{\mathrm{I}}+\gamma q_{\mathrm{I}}\right)
\end{array}\right.
$$

We summarize the optimal outcome in different cases just as in the former section.

Case 1: If $\frac{q_{\mathrm{Q}}-q_{\mathrm{I}}}{c_{\mathrm{Q}}-c_{\mathrm{I}}}<\frac{b}{\gamma\left(1-\alpha^{*}\right)}$, Apple chooses Intel and

$$
\left\{\begin{array}{c}
\alpha^{*}=\frac{b c_{\mathrm{Q}}-\gamma\left(1-\alpha^{*}\right)\left(q_{\mathrm{Q}}-q_{\mathrm{I}}\right)}{b} \\
1-\frac{T_{\mathrm{I}}^{2}}{X\left(T_{\mathrm{I}}\right)}+\frac{X\left(T_{\mathrm{I}}\right)}{3 a^{2}}, T_{I}>a \sqrt{\frac{(1-\bar{\alpha})^{3}}{1+\bar{\alpha}}} \\
\bar{\alpha}, T_{\mathrm{I}} \leq a \sqrt{\frac{(1-\bar{\alpha})^{3}}{1+\bar{\alpha}}} \\
m^{*}=\frac{a+\gamma\left(2 q_{\mathrm{I}}-q_{\mathrm{Q}}\right)}{2 b}+\frac{c_{\mathrm{Q}}}{2\left(1-\alpha^{*}\right)} \\
\Pi_{\mathrm{Q}}^{*}=\frac{\alpha^{*}\left(\left(1-\alpha^{*}\right)\left(a+\gamma\left(2 q_{\mathrm{I}}-q_{\mathrm{Q}}\right)\right)+b c_{\mathrm{Q}}\right)\left(\left(1-\alpha^{*}\right)\left(a+\gamma q_{\mathrm{Q}}\right)-b c_{\mathrm{Q}}\right)}{4 b\left(1-\alpha^{*}\right)^{2}} \\
\Pi_{\mathrm{A}}^{*}=\frac{\left(\left(b\left(c_{\mathrm{Q}}-c_{\mathrm{I}}\right)-\gamma\left(1-\alpha^{*}\right)\left(q_{\mathrm{Q}}-q_{\mathrm{I}}\right)\right)\left(\left(1-\alpha^{*}\right)\left(a+\gamma q_{\mathrm{Q}}\right)-b c_{\mathrm{Q}}\right)\right.}{2 b\left(1-\alpha^{*}\right)} \\
\left.4 b\left(1-\gamma q_{\mathrm{Q}}\right)-b c_{\mathrm{Q}}\right)^{2}
\end{array}\right.
$$


Case 2: If $\frac{q_{\mathrm{Q}}-q_{\mathrm{I}}}{c_{\mathrm{Q}}-c_{\mathrm{I}}} \geq \frac{b}{\gamma\left(1-\alpha^{*}\right)}$, Apple chooses Qualcomm and

$$
\left\{\begin{array}{c}
\alpha^{*}=\left\{\begin{array}{c}
w_{\mathrm{Q}}^{*}=\frac{b c_{I}+\gamma\left(1-\alpha^{*}\right)\left(q_{\mathrm{Q}}-q_{\mathrm{I}}\right)}{b} \\
1-\frac{T_{\mathrm{Q}}^{2}}{X\left(T_{\mathrm{Q}}\right)}+\frac{X\left(T_{\mathrm{Q}}\right)}{3 a^{2}}, T_{\mathrm{Q}}>a \sqrt{\frac{(1-\bar{\alpha})^{3}}{1+\bar{\alpha}}} \\
\bar{\alpha}, T_{\mathrm{Q}} \leq a \sqrt{\frac{(1-\bar{\alpha})^{3}}{1+\bar{\alpha}}} \\
p^{*}=\frac{a+\gamma\left(2 q_{\mathrm{Q}}-q_{\mathrm{I}}\right)}{2 b}+\frac{c_{\mathrm{I}}}{2\left(1-\alpha^{*}\right)} \\
\Pi_{\mathrm{Q}}^{*}=\frac{\left(\left(1-\alpha^{*}\right)\left(a+\gamma q_{\mathrm{I}}\right)-b c_{\mathrm{I}}\right)\left(\left(1-\alpha^{*}\right)\left(\alpha^{*} a+2\left(\gamma q_{\mathrm{Q}}-b c_{\mathrm{Q}}\right)\right)+\left(2-\alpha^{*}\right)\left(b c_{\mathrm{I}}-\gamma\left(1-\alpha^{*}\right) q_{\mathrm{I}}\right)\right)}{4 b\left(1-\alpha^{*}\right)^{2}} \\
\Pi_{\mathrm{I}}^{*}=0 \\
\Pi_{\mathrm{A}}^{*}=\frac{\left(\left(1-\alpha^{*}\right)\left(a+\gamma q_{\mathrm{I}}\right)-b c_{\mathrm{I}}\right)^{2}}{4 b\left(1-\alpha^{*}\right)}
\end{array}\right.
\end{array}\right.
$$

w h e r e $\quad X(T)=\sqrt[3]{3\left(\sqrt{81 a^{8} T^{4}+3 a^{6} T^{6}}-9 a^{4} T^{2}\right.}, \quad T_{\mathrm{I}}=b c_{\mathrm{Q}}-\gamma(1-\bar{\alpha})\left(q_{\mathrm{Q}}-q_{\mathrm{I}}\right)$, $T_{\mathrm{Q}}=b c_{\mathrm{I}}+\gamma(1-\bar{\alpha})\left(q_{\mathrm{Q}}-q_{\mathrm{I}}\right)$.

\subsubsection{Comparative Analysis}

To analyze whether Qualcomm should offer a rebate contract to Apple, we should compare the results in Eqs. (2.5) and (2.6) with those in Eq. (2.2). To simplify our analysis, we consider the case $\alpha^{*}=\bar{\alpha}$, that is, Qualcomm sets the highest royalty rate no matter whether Apple signs the rebate contract or not. Then, we need to calculate Qualcomm's profit difference in two situations, or the total profit difference of Qualcomm and Apple together, given Qualcomm will make Apple's profits in two situations meet at last through the rebate, i.e., $\Pi_{\mathrm{A}}^{1}=\Pi_{\mathrm{A}}^{2}$.

$$
\Delta=\Pi_{\mathrm{Q}}^{2}-\Pi_{\mathrm{Q}}^{1}=\left(\Pi_{\mathrm{Q}}^{2}+\Pi_{\mathrm{A}}^{2}\right)-\left(\Pi_{\mathrm{Q}}^{1}+\Pi_{\mathrm{A}}^{1}\right)
$$

where $\Pi_{\mathrm{Q}}^{i}$ and $\Pi_{\mathrm{A}}^{i}$ are respectively Qualcomm's and Apple's profit in situation $i, i=1,2$. Situation 1 refers to the case when Apple accepts the rebate while situation 2 represents the case when Apple refuses the rebate. If $\Delta<0$, Qualcomm can also benefit from the rebate contract. If $\Delta>0$, Qualcomm gets worse off and hence should not offer a rebate.

Supposing Qualcomm does not win the price competition with Intel, easily we have

$$
\begin{gathered}
\Pi_{\mathrm{Q}}^{1}+\Pi_{\mathrm{A}}^{1}=\frac{(3-2 \bar{\alpha})\left(a+\gamma q_{\mathrm{Q}}-b c_{\mathrm{Q}}\right)^{2}}{4 b(2-\bar{\alpha})^{2}} \\
\Pi_{\mathrm{Q}}^{2}+\Pi_{\mathrm{A}}^{2}=\frac{(1-\bar{\alpha})\left(a+\gamma q_{\mathrm{Q}}\right)-b c_{\mathrm{Q}}}{4 b(1-\bar{\alpha})^{2}}\left[\begin{array}{c}
(1-\bar{\alpha})\left(a+\gamma q_{\mathrm{Q}}\right)-b c_{\mathrm{Q}}+ \\
2 \bar{\alpha}\left((1-\bar{\alpha}) \gamma\left(q_{\mathrm{I}}-q_{\mathrm{Q}}\right)+b c_{\mathrm{Q}}\right)
\end{array}\right]
\end{gathered}
$$




$$
\begin{aligned}
& \Delta=\frac{\left((1-\bar{\alpha})^{2}\left(a+\gamma q_{\mathrm{Q}}\right)-b c_{\mathrm{Q}}\right)^{2}}{4 b(1-\bar{\alpha})^{2}(2-\bar{\alpha})^{2}}-\frac{\bar{\alpha} c_{\mathrm{Q}}\left(a+\gamma q_{\mathrm{Q}}-b c_{\mathrm{Q}}\right)}{2 b(1-\bar{\alpha})(2-\bar{\alpha})} \\
& +\frac{\bar{\alpha}\left((1-\bar{\alpha}) \gamma\left(q_{I}-q_{\mathrm{Q}}\right)+b c_{\mathrm{Q}}\right)\left((1-\bar{\alpha})\left(a+\gamma q_{\mathrm{Q}}\right)-b c_{\mathrm{Q}}\right)}{2 b(1-\bar{\alpha})^{2}}
\end{aligned}
$$

The sign of $\Delta$ is not apparent here. But we still attempt to answer the question whether Qualcomm should offer a rebate to Apple. It is obvious that situation 2 is equivalent to situation 1 when $\bar{\alpha}=0$. Moreover, when $\bar{\alpha}$ is very small, the differences between these two situations are also not distinct.

To testify our conjecture, we conduct a numerical analysis here. Supposing $b=\gamma=$ $1, c_{\mathrm{Q}}=2, c_{\mathrm{I}}=1, q_{\mathrm{Q}}=1, q_{\mathrm{I}}=0.5$, we plot out the different results of $\Delta$ in Fig. 2. As we can see in Fig. 1, when the royalty rate is small enough, $\Delta>0$ and Qualcomm is not suggested to offer a rebate to Apple from an economic perspective. When the royalty rate is relatively but not very high, it is beneficial for Qualcomm to implement the bundled rebate program.

In reality, the potential demand is very large in the smartphone market. Regulators usually set a low royalty rate cap in consideration of buyers' huge procurement cost of physical products. That is to say, $a$ is large and $\bar{\alpha}$ is small. Therefore, in this situation, we could come up with a similar conclusion that there is little possibility for Qualcomm to offer a rebate to Apple for an exclusive purpose.

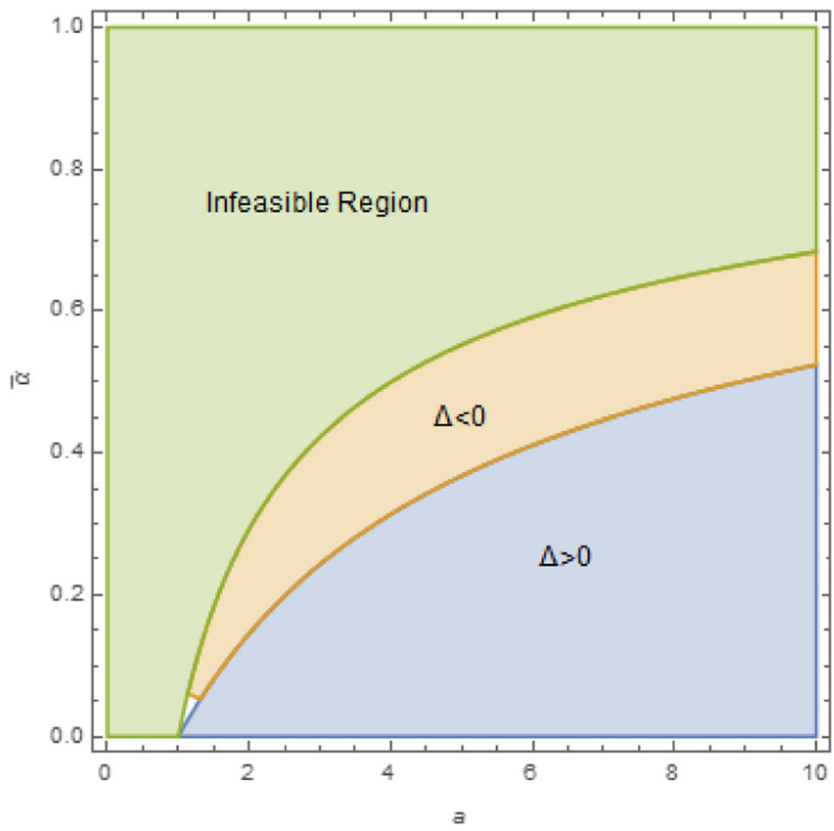

Fig. 2 Possible results in the single-stage non-exhaustive contract setting 


\subsection{Two-Stage Exhaustive Contract}

Supposing Intel will improve its material quality to the same level as Qualcomm in the long term, does Qualcomm have a larger incentive to offer a rebate? We examine the long-term effect of rebate in excluding potential competitors by supposing a two-stage exhaustive contract. To simplify our analysis, we only study the situation that the bundled contract is exhaustive, and the rebate is still assumed to be a lump sum here.

\subsubsection{Apple Signs the Rebate Contract}

If Apple accepts the rebate contract, then it is forced to procure from Qualcomm in both stages. The optimal profits for Qualcomm and Apple in equilibrium are given by the following equations.

$$
\left\{\begin{array}{c}
\Pi_{\mathrm{Q}}^{*}=\frac{\left(a+\gamma q_{\mathrm{Q}}-b c_{\mathrm{Q}}\right)^{2}}{4 b}-r \\
\Pi_{\mathrm{A}}^{*}=\frac{\left(a+\gamma q_{\mathrm{Q}}-b c_{\mathrm{Q}}\right)^{2}}{8 b}+r
\end{array}\right.
$$

\subsubsection{Apple Does Not Sign the Rebate Contract}

If Apple rejects the rebate, then the competition in the second stage will get quite intense, which results in zero profits for both Qualcomm and Intel. However, in the first stage, we reach to the similar outcomes to those in the single-stage exhaustive contract setting. In total, we could get the following profits for all parties.

Case 1: If $m_{\mathrm{Q}} \geq m_{\mathrm{I}}$, Apple chooses Qualcomm in the first stage and

$$
\left\{\begin{array}{c}
\Pi_{\mathrm{Q}}^{*}=\frac{\left(a+\gamma q_{\mathrm{I}}-b c_{\mathrm{I}}\right)\left[\gamma\left(q_{\mathrm{Q}}-q_{\mathrm{I}}\right)-b\left(c_{\mathrm{Q}}-c_{\mathrm{I}}\right)\right]}{2 b} \\
\Pi_{\mathrm{I}}^{*}=0 \\
\Pi_{\mathrm{A}}^{*}=\frac{\left(a+\gamma q_{\mathrm{I}}-b c_{\mathrm{I}}\right)^{2}+\left(a+\gamma q_{\mathrm{Q}}-b \mathrm{c}_{\mathrm{Q}}\right)^{2}}{4 b}
\end{array}\right.
$$

Case 2: If $m_{\mathrm{Q}}<m_{\mathrm{I}}$, Apple chooses Intel in the first stage and

$$
\left\{\begin{array}{c}
\Pi_{\mathrm{Q}}^{*}=0 \\
\Pi_{\mathrm{I}}^{*}=\frac{\left(a+\gamma q_{\mathrm{Q}}-b c_{\mathrm{Q}}\right)\left[b\left(c_{\mathrm{Q}}-c_{\mathrm{I}}\right)-\gamma\left(q_{\mathrm{Q}}-q_{\mathrm{I}}\right)\right]}{2 b} \\
\Pi_{\mathrm{A}}^{*}=\frac{\left(a+\gamma q_{\mathrm{Q}}-b c_{\mathrm{Q}}\right)^{2}}{2 b}
\end{array}\right.
$$




\subsubsection{Comparative Analysis}

If $m_{\mathrm{Q}}<m_{\mathrm{I}}$, to ensure Apple's cooperation, Qualcomm must have $r^{*} \geq \frac{3\left(a+\gamma q_{\mathrm{Q}}-b c_{\mathrm{Q}}\right)^{2}}{8 b}$, which is much higher than its profit. As a result, it is reasonable for Qualcomm not to offer such a rebate.

If $m_{\mathrm{Q}} \geq m_{\mathrm{I}}$, the least rebate would be

$$
r^{*}=\frac{2 m_{\mathrm{I}}^{2}+m_{\mathrm{Q}}^{2}}{8 b}
$$

Then, Qualcomm's net profit with the rebate contract signed is $\frac{m_{\mathrm{Q}}^{2}-2 m_{1}^{2}}{8 b}$. We compare this profit with its profit when the rebate is rejected and the price war happens.

$$
\Delta=\Pi_{\mathrm{Q}}^{2}-\Pi_{\mathrm{Q}}^{1}=\frac{m_{\mathrm{I}}\left(m_{\mathrm{Q}}-m_{\mathrm{I}}\right)}{2 b}-\frac{m_{\mathrm{Q}}^{2}-2 m_{\mathrm{I}}^{2}}{8 b}=\frac{2 m_{\mathrm{I}}^{2}-\left(2 m_{\mathrm{I}}-m_{\mathrm{Q}}\right)^{2}}{8 b}
$$

Then, we propose Qualcomm's strategies in different cases. If $m_{\mathrm{Q}} \geq(2+\sqrt{2}) m_{\mathrm{I}}$, Qualcomm will offer the least rebate $r^{*}$ to Apple. If $m_{\mathrm{I}} \leq m_{\mathrm{Q}}<(2+\sqrt{2}) m_{\mathrm{I}}$, Qualcomm will not offer any rebate to Apple out of economic concerns. Therefore, we put forward the following proposition.

Proposition 2 In a two-stage exhaustive contract setting, it is economically reasonable for Qualcomm to provide an exclusive rebate contract to Apple if and only if $m_{\mathrm{Q}} \geq(2+\sqrt{2}) m_{\mathrm{I}}$, and the optimal rebate is $\frac{2 m_{\mathrm{I}}^{2}+m_{\mathrm{Q}}^{2}}{8 b}$.

Corollary 1 The optimal rebate increases with $m_{\mathrm{Q}}$ and $m_{\mathrm{I}}$.

When Qualcomm obtains a strong quality advantage over Intel, it can retain its huge profit in two stages by providing an acceptable lump-sum rebate to Apple. At the same time, increasing $m_{\mathrm{Q}}$ and $m_{\mathrm{I}}$ signify growing possible demand, and hence, Apple could get a higher profit if the price competition really happens. Therefore, Apple expects a higher rebate in compensation for profit loss after signing the so-called exclusive contract.

\section{Discussion}

As a leader in 4G-LTE network industry, Qualcomm has a dominant advantage in its market share and modem chip quality over other companies. ${ }^{13}$ In the lawsuit with Apple, Qualcomm is accused of excluding competitors and violating the antitrust law by means of providing a bundled rebate contract. However, our single-stage economic models indicate that in most cases, it is unnecessary for Qualcomm to provide such an exclusive contract. The underlying reason might be that Qualcomm's quality advantage can guarantee its leading position in the market competition, especially when trading with Apple. As we know, Apple is a highly

\footnotetext{
${ }^{13}$ See Trefis Team, Why Qualcomm Remains The No.1 Player In Cellular Baseband Forbes (2014), available at: https:/www.forbes.com/sites/greatspeculations/2014/07/11/why-qualcomm-remains-the-no-1-player-in-cellularbaseband-2/\#1449fd0f22fd (last visited November 19, 2018).
} 
innovative company and extraordinary customer experience is this company's first concern. To this end, Apple makes great efforts to improve its product quality. Therefore, there is no need for Qualcomm to discourage Apple from choosing another supplier by providing benefits except for good quality.

However, despite its advantages, Qualcomm is probably predicting shrinkage in its quality advantage and the threat of losing its leading role in the industry. For example, the latest Apple iPhone $\mathrm{X}$ integrates an Intel cellular modem, though Qualcomm-powered devices are still more reliable with the evidence that the Android phones using Qualcomm's latest Snapdragon 845 mobile chip saw 53\% faster typical downloads, $103 \%$ faster worst-case downloads, and $32 \%$ lower typical latency. ${ }^{14}$ To validate this viewpoint, we analyzed a two-stage exhaustive contract and found that Qualcomm will offer an attractive rebate to consolidate its long-term cooperation with Apple although its current quality advantage is remarkable. Nevertheless, when its quality advantage is sufficiently weak, it is not practical for Qualcomm to offer any rebate from an economic perspective. When suppliers get closer to each other in quality and cost, Apple could benefit much more from the price war. As a consequence, it could be difficult to persuade Apple to accept the rebate and to avoid the intense competition in the future. To this extent, Qualcomm probably designed a rebate program to ensure its profit in case that other companies threaten its leading position.

\section{Conclusion}

In this paper, we take Qualcomm's lawsuit litigated in 2017 as our example. By conducting a thorough analysis in this paper, we find that Qualcomm should not have provided the bundled rebate and loyalty discount program for Apple because it is not profitable for Qualcomm in a one-shot game and it is possible to violate antitrust law. However, according to our two-stage modeling and case analyses between six cases and Qualcomm's situation, we can infer that Qualcomm may still have business and legal reasons to do so insistently. In terms of business concerns, Qualcomm may desire to avoid its future losses resulting from price competition. This conclusion makes sense when taking the rapid development in telecommunications, for example, 5G technologies, into account.

Although Apple and Qualcomm settled their lawsuits in late April 2019, ${ }^{15}$ it does not mean the issues of bundled rebate and loyalty discount program have been reconciled. For firms in the modem chip industry, on the one hand, they have to carefully design and manage their SEP licensing strategies. For instance, they might separate the pricing of SEP licenses and modem chips so that they can escape the potential violation of the bundling. On the other hand, it is sort of risky and economically unwise for a chipset supplier and a patent holder to maintain long-term businesses with manufacturers by means of potentially exclusive contracts, or a bundled rebate program as discussed in this paper. In essence, it is the quality difference between upstream chipset suppliers that makes the bundled rebate work in the long run in this paper. Therefore, instead of focusing too much on contracting, chipset suppliers like Qualcomm are suggested to improve their chipset quality at first. Finally, we do not know

\footnotetext{
${ }^{14}$ See Ryan Shrout, Qualcomm claims wireless dominance over Intel and Apple MarketWatch (2018), available at: https://www.marketwatch.com/story/qualcomm-claims-wireless-dominance-over-intel-and-apple-2018-07-23 (last visited November 19, 2018).

${ }^{15}$ See https://www.nytimes.com/2019/04/16/technology/apple-qualcomm-settle.html (last visited April 19, 2019 ) .
} 
the impact on the society if the Federal Court decides that Qualcomm's implementing the bundled rebate and loyalty discount program is illegal. Is that beneficial to end-users if SEPs and modem chips cannot be bundled together? We look forward to some future studies.

Open Access This article is distributed under the terms of the Creative Commons Attribution 4.0 International License (http://creativecommons.org/licenses/by/4.0/), which permits unrestricted use, distribution, and reproduction in any medium, provided you give appropriate credit to the original author(s) and the source, provide a link to the Creative Commons license, and indicate if changes were made.

\section{References}

Bork R (1978) The antitrust paradox. basic books, New York

Bowman WS Jr (1957) Tying arrangements and the leverage problem. Yale Law J 67(19):20-36

Chen J, Liang L, Yao D-q (2017) An analysis of intellectual property licensing strategy under duopoly competition: component or product-based? Int J Prod Econ 193:502-513

Crane DA (2012) Tying and consumer harm. Competition Policy Int 8(2):27-33

DeGraba P (2013) Naked exclusion by a dominant input supplier: exclusive contracting and loyalty discounts. Int J Ind Organ 31(5):516-526

Director A, Levi EH (1956) Law and the future: trade regulation. Northwest Univ Law Rev 51:281-296

Elhauge ER (2009) Tying, bundled discounts, and the death of the single monopoly profit theory. Harvard Law Rev 123(2) Available at SSRN: https://ssrn.com/abstract=1345239

Evans DS, Salinger M (2005) Why do firms bundle and tie? Evidence from competitive markets and implications for tying law. Yale J Regulat 22 Available at: https://igitalcommons.law.yale.edu/yjreg/vol22/iss1/3

Graf J (2014) The effects of rebate contracts on the health care system. Eur J Health Econ 15(5):477-487

Hovenkamp E (2017) Tying, exclusivity, and standard-essential patents. Columbia Sci Technol Law Rev 19:79135

Kobayashi BH (2005) Does economics provide a reliable guide to regulating commodity bundling by firms? A survey of the economic literature. J Compet Law Econ 1(4):707-746

Llobet G, Padilla J (2016) The optimal scope of the royalty base in patent licensing. J Law Econ 59(1):45-73

Melamed AD, Shapiro C (2017) How antitrust law can make FRAND commitments more effective. Yale Law J 127:2110

Posner RA (1978) The Chicago school of antitrust analysis. Univ Pa Law Rev 127:925-948

Posner RA (2001) Antitrust law: an economic perspective, 2nd edn

Posner RA, Easterbrook FH (1981) Antitrust, American Casebook Series. West Publishing, 2th edition, Chicago.

Sagi G (2014) A comprehensive economic and legal analysis of tying arrangements. Seattle Univ Law Rev 38(1)

Stigler GJ (1968) The organization of industry, chap. A note on lock booking. Homewood: Irwin.

Whinston MD (1990) Tying, foreclosure, and exclusion. Am Econ Rev 80(4):837-859

Wong-Ervin K, Hicks E, Slonim A (2016) Tying and bundling involving standard-essential patents. George Mason Law Rev 24:1091

Yang F, Jiao C, Ang S (2019) The optimal technology licensing strategy under supply disruption. Int J Prod Res: 57(7):2057-2082

Publisher's Note Springer Nature remains neutral with regard to jurisdictional claims in published maps and institutional affiliations. 